\title{
Eugène Loos, Leslie Haddon and Enid Mante-Meijer (eds.) (2012). Generational Use of New Media. Farnham: Ashgate, 236 pp. ISBN 9781409426578 (hardback)
}

\author{
REVIEWED by SELMA KADI*
}

The book Generational Use of New Media gives a good overview of a range of perspectives for studying new media use by different generations. The diversity of perspectives is a result not only of the multidisciplinarity of the presented research but also of the different types of links between the main topic and the specific research questions: generational use of new media is treated as a starting point for investigations of one generation's use, as a basis for exploring different generations' perceptions and experiences with the same media, and as a concept to be critically examined, either in terms of its accompanying assumptions or its analytical value. The book is divided into three parts, bringing together studies focusing on younger people's use, older people's use, and research that takes a comparative approach.

One thread that runs through many chapters is the discussion of the concept of digital immigrants and natives developed by Prensky (2001). He originally used these terms to describe differences between students and teachers, arguing that the latter have to adapt their teaching to a changed student population of digital natives. According to Prensky, younger people, who were born into digital society, are advantaged in

* Selma Kadi, International Centre for Ethics in the Sciences and Humanities, Eberhard Karls University Tübingen, Tübingen, Germany 
comparison to everybody else who had to learn the skills necessary to use new media later in their lives. Generational Use of New Media also includes a discussion of indicators to determine the first cohort of digital natives, concluding that this first cohort varies by country, depending on the respective national history of media use. The authors of this volume also present empirical studies which critically interrogate the difference in skills between the digital native and digital immigrant generation, demonstrating, for example, a lack of skills among younger people and older people's content-related Internet skills, which are unmatched by younger people.

The first part of the book focuses on younger people's media use, including studies on the use of new media by children, teenagers and students. Haddon distinguishes four different levels of mediation exercised by parents and compares the mediation of younger and older children's use. Cardoso, Espanha and Lapa study mediation by parents from the perspective of Portuguese teenagers. Bowens researches whether the Internet, as a peer-dominated space, shapes younger people's morality in a way which excludes parents. In the final chapter of the first part, Herold questions the concept of digital natives and digital immigrants. He distinguishes four different areas (technical problems, software problems, data-usage problems, critical awareness problems) in which his students lacked skills.

The second part of the book includes studies analysing new media use by the "oldest old," proposing guidelines for more accessible website design and suggesting improvements of rail ticket vending machines. Hagberg employs a techno-biographical approach to research information and communications technology (ICT) use among the oldest old in Sweden. He discusses different factors and mechanisms (e.g. anticipatory ageing) that contribute to the lower uptake of ICTs, resulting in the oldest old not renewing their "material room" in the "technological landscape" (ICTs available in their community). Hagberg argues that the oldest old have the right to have access to new media and asks whether they should, at the same time, have the right to refrain from using new technologies. Chisnell and Redish develop a detailed list of recommendations for designing websites for older people, arguing that they also increase accessibility for other groups. Schreder, Siebenhandl, Mayr and Smuc find that older people's lower usage of the studied ticket machines for rail travel is due to 
problems with the design of the interface and low self-efficacy beliefs of potential users.

The third part includes a comparison of the perception of new ICTs by digital natives and digital immigrants, an analysis of the prevalence of four types of Internet skills among different age groups and research on the navigating behaviour of younger and older people. Lugano and Peltonen demonstrate that digital immigrants and digital natives hold different views on specific communication media, such as postcards, email and social networking sites. Van Deursen analyses Internet skills of different generations and shows that younger people score higher on "mediumrelated skills" (operational and formal skills), but that "content-related skills" (finding information, the ability to reach a particular goal) increase with age. Loos and Mante-Meijer study differences in age in terms of navigating behaviour on websites through the analysis of eye movements. Although younger people complete certain tasks faster, the frequency of Internet use is more important for explaining differences in navigation behaviour than age.

In the second part of the book, which presents research on older people's use of new media, authors differ in their conceptualisations of age. Although there is a consensus that age includes more than physical decline, what else it is varies. Hagberg distinguishes three different aspects (biological age, social age and generation identity), Chisnell and Redish state that age is more than a collection of disabilities and Schreder et al. discuss it as a mixture of physical limitations, low self-efficacy beliefs, a lack of digital literacy and low motivation to use digital technology. In Chisnell and Redish's chapter, the authors emphasise that age is not sufficiently described through disabilities. However, their research perspective, which aims to generate design recommendations for improving the usability of websites for older people, seems to make this a particularly challenging task and leads them to effectively consider ageing only in terms of physical ageing processes.

Children's use is studied with a focus on mediation exercised by parents. While mediation by parents is certainly an important aspect, it would also be interesting to present findings from studies on children's use in which the involvement of parents is not the only focus. However, this emphasis on parents, either in terms of mediation or regarding 
International Journal of Ageing and Later Life

questions around the uptake of peer versus parent morality, means that power relations are put upfront in these studies. If we assume that power relations, however different, also shape the use of new media by older people in some way, we find that there is much less concern with them in the chapters on older people's use. Another important point regarding research on ageing is Loos and Mantje-Meijer's call to theorise age more in studies that include it as an explanatory variable.

The main strengths of the book are the multiple perspectives which are brought together around the concept of generational media use and the critical examination of the description of older users as less and younger users as more skilled. This book is a valuable contribution to the fields of media studies, research on new media use by children and new media use in later life. It unites studies from multiple disciplines, including usability research, media studies and ageing research. The collection enables readers to gain a good understanding of various on-going debates linked to the concept of generations in research on new media use.

\section{Reference}

Prensky, M. (2001). Digital natives, digital immigrants. On the Horizon 9(5): $1-6$. 